\title{
Valuing Long-Term Leases: The Option to Redevelop
}

\author{
DENNIS R. CAPOZZA \\ Professor of Finance, School of Business, University of Michigan, Ann Arbor, MI 48109-1234 \\ GORDON A. SICK \\ Associate Professor of Finance, Faculty of Management, University of Calgary, Calgary, Alberta, Canada \\ T2N $1 N 4$
}

\begin{abstract}
Long-term leases on property are popular in many jurisdictions, both with private vendors and with local governments who want to retain future control over land use. A puzzling issue for vendors and purchasers has been how to value these leased properties relative to fee-simple properties. Simple present-value models suggest that there should be little difference between the price of fee-simple land and the price of long-term leases. Transaction prices in Canada on 80-year to 100-year residential leases, however, are 20 percent to 40 percent less than comparable fee-simple properties. We outline a financial model for valuing leased properties. The value of the option to upgrade or redevelop is considered. We show that the large part of the discount of leased properties from fee-simple properties can be explained by this option to redevelop.
\end{abstract}

Keywords: Lease, fee-simple, real option, redevelop

Institutions and governments as well as private individuals often choose to lease real estate assets for a finite period of time rather than sell a fee-simple title. For example, private houses in Canada's National Parks are built on leased land. Similarly, Indian bands lease lots to homeowners. In many U.S. cities-for example, Baltimore and Syracuse-houses are built on ground leases. In both the United States and Canada, mineral rights are leased to petroleum companies.

Presumably there are good reasons why these asset owners do not sell their properties outright. These institutions may want to maintain long-term environmental control of the property, or the property may represent an important legacy or heritage. Income tax may be a factor for private individuals and corporations (Luzatto, 1987).

The price to be paid for retaining this control can be high, however. For example, 80-year to 90-year prepaid leases of land with single-family dwellings in the Salish Park area of Vancouver sell for a 20 percent to 40 percent discount from comparable fee-simple property in the adjacent Dunbar and Kerrisdale areas.

In a simple discounted cash flow framework, one would calculate the discount as the difference between the present value of an 80-year annuity and the present value of a perpetuity. However, this accounts for less than a 1 percent discount under reasonable assumptions.

In this article, we investigate another source of the discount-the option to redevelop. We believe that the lessee is less inclined to perform future upgrades to the property than the fee-simple owner because the lessee loses the benefit of the upgrade at the end of the lease. Since the option to upgrade the property is valuable, leased property should trade at a discount because of the impairment of the option. 
We show that a substantial portion of the discount of leased land can be explained by these distorted incentives. Moreover, this research predicts the relationships between these discounts and other observable quantities, such as growth rates, risk levels, conversion density, and rent multipliers.

The option to upgrade or redevelop a property is an example of a real option. ${ }^{1}$ Real options share some characteristics with financial options traded on securities exchanges but are created by the presence of real investment opportunities. Many researchers are now treating the decision to exploit mineral and timber reserves with the theory of real options. ${ }^{2}$ A noteworthy characteristic of real option theory is that it highlights a weakness in blind application of the popular net present value rule, wherein it is considered appropriate to accept a project as long as the present value of the benefits exceeds the present value of the costs. ${ }^{3}$ Real option theory recognizes that an adopted project exposes the owner to downside risk. However, the owner of an option to adopt the project at some point in the future is somewhat insulated from downside risk, because the option need not be exercised if, in the future, the present value of the costs exceeds the present value of the benefits. Thus, real option theory specifies a hurdle net present value that is strictly greater than zero in order to provide a cushion against the downside risk. ${ }^{4}$

Research on leases tends to focus on the tax aspects of the lease-buy decision (Myers, Dill, and Bautista, 1976). McConnell and Schallheim (1983) have studied the option features of operating leases, including the option to cancel or extend the lease, and the option to purchase the leased asset at maturity. In the research presented here, we discuss noncancellable financial or capital leases. The treatment of the option to upgrade the real asset is unique to our study. ${ }^{5}$ We also believe that this is the first theoretical study to address the large discounts of leased property from fee-simple property.

In the next section we outline the features of leased and fee-simple property and the nature of the redevelopment decision under certainty. In the third section we extend the model to the uncertainty case. The fourth section presents the results, and the final section summarizes and concludes.

\section{Leased and fee-simple property}

Under the terms of both leased and fee-simple property, there is a right to unobstructed use of the property for a certain length of time, subject to any regulations imposed by government. The difference is that while the term is indefinite, (i.e., infinite) for fee-simple property, the term is finite for leased property (e.g., 99 years). For the purposes of analysis, then, fee-simple property can be viewed as an extreme case of leased property where the term of the lease goes to infinity. However, an important consideration when valuing longterm leases is the effect of an impending expiration of the lease on the value of the option to redevelop.

\subsection{The density upgrade process}

We assume that an upgrade increases density from one unit of space to $q$ units. That is, if the annual rental of one unit of space is $R$, then the annual rental on the property after 
conversion is $q R$. The landowner must jointly calculate the optimal conversion density, $q^{*}(T)$, and the hurdle rent, $R^{*}(T)$, for a lease with $T$ years to expiry. That is, the property is renovated to a density, $q^{*}(T)$, as soon as the rent $R$ first exceeds the hurdle rent, $R^{*}(T)$. At times, it is convenient to think in terms of the equivalent price of a unit of fee-simple land, $P^{*}(T)$, that corresponds to the hurdle rent.

We will first analyze redevelopment under certainty since this is a useful limiting case of the uncertainty model. Many of the results from the uncertainty case also arise in the certainty case. In both cases we have enhanced discounts between the lease and fee-simple properties because of the distorted conversion policies to a lease holder. This distortion causes the lessee to convert later and at a lower density.

\subsection{Conversion process}

We assume that, when land is converted to a higher density, the resulting space per unit of land is given by

$$
q(k)=k^{\gamma}
$$

where $\gamma=$ capital elasticity or efficiency of production, $k=$ amount of capital per unit of land.

We assume decreasing returns to scale in the construction process $(\gamma<1)$. If $\gamma=1$, the process is perfectly efficient, because a 1 percent increase in capital generates a 1 percent increase in density. If $\gamma=1 / 2$, the conversion is less efficient because an extra 1 percent of capital only increases density by $1 / 2$ percent. If $\gamma=0$, the density canrot be increased at any cost. This latter case corresponds to a model in which there is no option to upgrade property.

Assume the cost of applying $k$ units of capital is $k c$ where $c$ is the cost of a unit of capital. The value of land after conversion, therefore, is $k^{\gamma} P$, and the net present value of conversion is $k^{\gamma} P-k c$. Figure 1 illustrates how the land value jumps at the conversion date.

\subsection{Certain rent growth}

Let $^{6} R(t)=R(0)+g t$. The value of one unit of leased land is

$$
P(R, T)=\left(\frac{R(0)}{r}+\frac{g}{r^{2}}\right)-\left(\frac{R(0)}{r}+\frac{g}{r^{2}}+\frac{g}{r} T\right) e^{-r T}
$$

where $r$ is the riskless real rate of interest which is constant over time.

For fee-simple property the horizon is infinite so that $T=\infty$ and equation (2) becomes

$$
P(R(t) ; \infty) \equiv \mathfrak{P}(R(t))=R(t) / r+g / r^{2} .
$$

At time $T$, when the lease matures, the rent will be $R(T)=R+g T$ where $R=R(0)$, and fee-simple property will be worth

$$
P(R+g T, \infty)=(R+g T) / r+g / r^{2}
$$


Thus we can interpret equation (2) as saying that the value of leased property is equal to the value of fee-simple property minus the present value of the fee-simple property that is "lost" when the lease matures at time $T$.

Using equations (2) and (3), the ratio of the value of leased to fee-simple property is

$$
P(R, T) / P(R, \infty)=1-\exp (-r T)\left(1+\frac{g T}{R+g / r}\right) .
$$

If we adopt a policy of converting at time $\tau$ to a density $q$, then the value at time 0 is

$$
W(R, \tau, k ; T)=P(R, \tau)+e^{-r \tau}(q(k) P(R+g \tau, T-\tau)-k c)
$$

That is, we have one unit of rent from time 0 to $\tau$ and $q$ units of rent from $\tau$ to $T$. Only one redevelopment is allowed.

Let the optimal values be $\tau^{*}$ and $k^{*}$. In the certainty model, the rent at the time of conversion is $R+g \tau^{*}$. We must determine $\tau^{*}$ and $k^{*}$ jointly.

Suppose we convert when the unit price of a lease is

$$
P^{*}=P\left(R+g \tau^{*}, T-\tau^{*}\right)
$$

In equation (5), given $\tau^{*}$, we must choose an optimal amount of capital, $k^{*}$, by solving

$$
\max _{k} q(k) P^{*}-k c
$$

where $q(k)=k^{\gamma}$.

The first order condition is $\gamma k^{*(\gamma-1)} P^{*}=c$ or

$$
k^{*}=\left(\frac{\gamma P^{*}}{c}\right)^{1 /(1-\gamma)}
$$

Now we hold $q=q\left(k^{*}\right)$ fixed and choose $\tau^{*}$ to maximize equation (5). The solution is

$$
\tau^{*}=\frac{1}{r}-\frac{r P(R, T)}{g}-\frac{r k^{*}(T) c}{g\left(1-k^{*}(T)^{\gamma}\right)} .
$$

The time to conversion depends on the initial rent $R$, but the corresponding hurdle price $P *$ depends only on the remaining time to maturity.

Equations (6),(8), and (9) jointly determine $k^{*}, \tau^{*}$, and $P^{*}$. Since they appear to have no analytic solution, we numerically search for a solution by studying all possible $\tau \in[0$, $T$ ] and by calculating $k^{*}$ from equations (2) and (8). In equation (5), this gives $W(R, \tau$, $\left.k^{*}(\tau) ; T\right)$. By using numerical search, we can solve for $\tau^{*}$ in the problem

$$
\max _{\tau \in[0, T]} W\left(R, \tau, k^{*}(\tau) ; T\right)
$$


This search also covers the policy of no conversion by setting $\tau=T$, because the lease is worthless at maturity, that is, $P(R+g T, 0)=0$ so that $k^{*}(T)=0$.

Figure 1 illustrates how property value will vary over time when rents are certain. The initial rent at time 0 is $R=\$ 10 /$ year, the growth rate is $\$ .50 /$ year, and the interest rate is 5 percent per year. The initial term of the lease is $T=100$ years. Note that property values are shown on a logarithmic scale. The bottom two curves show how property values increase when there is no option to upgrade the property. Initially, leased property and fee-simple property have almost identical values, but the leased property reaches a maximum value of about $\$ 800$ at the 60 th year and declines to a value of $\$ 0$ at maturity, while the fee-simple property continues to increase in value.

The top two curves indicate how property values increase if there is a one-time option to upgrade the property with a capital elasticity of conversion $\gamma=.5$ and a conversion cost of $c=\$ 100$ per unit of capital. In this case, it is optimal to convert fee-simple property at $\tau=28.3$ years to a density of $q=3.4$. We have shown the jump in value that occurs in that year as rents increase by a factor of 3.4. It is optimal to convert the leased property earlier (at $\tau=26$ years) and to a lower density $(q=3.1)$. Thus the loss of rents after the termination of the lease makes the upgrade process less profitable, so the property is upgraded to a lower density. Also, the property is upgraded earlier in order to capture more conversion benefits before the lease terminates. We provide other comparative statics in the next section.

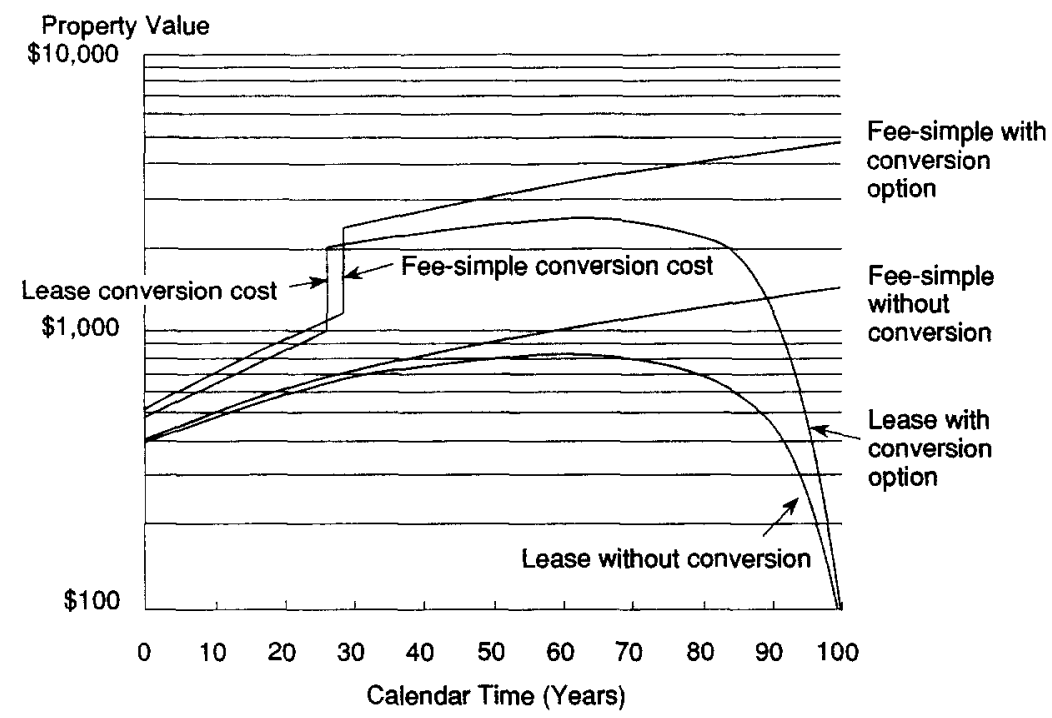

Figure 1. Prices of various types of property over time. Rent growth is $\$ 0.50 /$ year, initial rent is $\$ 10 /$ year, and real interest rate is 5 percent per year. Capital elasticity of conversion is 0.5 , and cost of one unit of conversion capital is $\$ 100$. Lease tenure is initially 100 years. Fee-simple land is optimally upgraded after 28.3 years to density of 3.4. Leased land is optimally upgraded after 26.0 years to density of 3.1 . 


\section{The uncertainty model}

Our model for uncertain rents is an extension of our earlier model of land development under uncertainty (Capozza and Sick, 1991) ${ }^{7}$ In the fee-simple problem the solution is a time-invariant free boundary problem that lends itself to analytical solution. The finite horizon of a lease necessitates numerical methods.

\subsection{The stochastic process}

We assume that rent, $R$, per unit of space follows the additive diffusion given by

$$
d R=g d t+\sigma d z
$$

That is, suppose there is a systematic pricing factor $f$, such that equilibrium rates of return follow

$$
E\left[\frac{d P+R d t}{P}\right]=r d t+\lambda \operatorname{cov}(d P / P, d f)
$$

where $P$ is the price of an asset paying a dividend at the rate $R .^{8}$ Define $b$ by $b d t=\operatorname{cov}(d R$, $d f)$. Let

$$
\hat{g}=g-\lambda b \text { (risk-adjusted growth rate). }
$$

Then the price of fee-simple land without the option to upgrade (see Sick, 1989; Capozza and Sick, 1991) is

$$
P(R)=\frac{R}{r}+\frac{\hat{g}}{r} .
$$

Therefore,

$$
d P=g / r d t+\sigma / r d z
$$

\subsection{The value of a lease}

Let $W^{*}(R, T)$ be the value of the lease with the remaining tenure $T$ under an optimal conversion policy. Let $k^{*}\left(R^{*}(T)\right)$ be the optimal conversion density and $R^{*}(T)$ be the optimal hurdle rent for conversion with $T$ years to maturity. The dependence on $T$ is dropped for fee-simple land $(T=\infty)$, that is, $W^{*}(R, \infty)=W^{*}(R)$.

This gives the boundary condition

$$
\begin{aligned}
& W\left(R^{*}, T\right)=\left(k^{*}\left(R^{*}\right)\right)^{\gamma} P\left(R^{*}, T\right)-c k^{*}\left(R^{*}\right) \\
& W^{\prime}\left(R^{*}, T\right)=\left(k^{*}\left(R^{*}\right)\right)^{\gamma} .
\end{aligned}
$$


Condition (14) says that option value at conversion equals net proceeds from conversion. Condition (15) is the smooth-pasting condition or first order condition.

As an extension to the certainty case, the value of one unit of nonconvertible leased land with tenure $T$ is

$$
\begin{aligned}
P(R, T) & =\int_{0}^{T} e^{-r t}(R+\hat{g} t) d t \\
& =\left(\frac{R}{r}+\frac{\hat{g}}{r^{2}}\right)-e^{-r T}\left(\frac{R+\hat{g} T}{r}+\frac{\hat{g}}{r^{2}}\right)
\end{aligned}
$$

The first term is the value of fee-simple land and the second is the present value of the fee-simple land lost at the end of the lease. Note that the risk-adjusted expected rent at the end of the lease is $R+\hat{g} T$.

We also have the same condition of optimal density as in the certainty case. Given a conversion price, $P^{*}=P\left(R^{*}, T\right)$, the optimal density is

$$
k^{*}=\left(\frac{\gamma P^{*}}{c}\right)^{1 /(1-\gamma)}
$$

As in the certainty case, we must determine the optimal density and hurdle rent jointly. With leased land, we must use a binomial tree or time-price grid. At each point in time and at each rental rate, we solve for the optimal density and then test whether it is optimal to convert at $(R, t)$ with capital $k^{*}(R)$, or whether it is best to keep the option alive.

We have the following standard ${ }^{9}$ partial differential equation for the value of a lease, $W(R, T)$

$$
r W=R+1 / 2 \sigma^{2} W_{R R}(R, T)-W_{T}+\hat{g} W_{R} .
$$

The left side of equation (18) is the required risk-neutral return. The four terms on the right side are, respectively, the rent cash flow, the Ito drift due to concavity of $W$ and random variation in $R$, the time decay as maturity approaches, and the risk-neutralized rent drift in $W$.

\subsection{Solution for fee-simple value}

There are two equivalent approaches to analyzing these real options. Each leads to the same solution, but in some situations, one approach is easier to implement than the other. The first approach involves solving the partial differential equation (18) for the value of the option as a function of time and the service flow. It is solved subject to the boundary conditions (14), (15), and (17).

In the second, the problem is treated as an extended decision tree with binary or Bernoulli probabilities. That is, at each node of the tree, the property owner decides whether to renovate, and nature then determines whether the underlying service flow increases or decreases. The appropriate probability for the up-down moves is selected as a synthetic probability that accounts for systematic risk. 
There are two attractive features associated with this binomial approach. First, the decision tree is easy to interpret economically and intuitively. Second, the decision tree can be implemented with standard two-dimensional spreadsheet software on a personal computer, even though the spreadsheet is large and taxes the memory and speed of the computer. is ${ }^{10}$

For fee-simple land $W_{T}=0$. The solution to the differential equation (18) subject to (14)

$$
W(R)=P(R)+\left\{\left[q\left(k\left(R^{*}\right)\right)-1\right] P\left(R^{*}\right)-c k\left(R^{*}\right)\right\} e^{-\alpha\left(R^{*}-R\right),}
$$

where $\alpha=\left(\left(\hat{g}^{2}+2 \sigma^{2} r\right)^{1 / 2}-\hat{g}\right) / \sigma^{2}$.

The first term in (19) is the value of future rents given the current density. The second term is the value of the option to convert to a higher density at some future time.

We now choose $R^{*}$ to maximize $W$. Given equation (17) for density, we use the smooth pasting condition (15) (first order condition of the maximization of $W$ with respect to $R^{*}$ ) to select $R^{*}$. This gives

$$
P^{*}=\frac{R^{*}}{r}+\frac{\hat{g}}{r^{2}}=\frac{c k^{*}}{k^{* \gamma}-1}+\frac{1}{\alpha r} .
$$

Equations (17) and (20) can be solved simultaneously for $k^{*}$ and $R^{*}$ using numerical methods. Care must be taken to ensure that an optimum rather than a saddle point results.

\subsection{Solution for leased value}

The partial differential equation (18) is difficult to solve analytically. We use a 40-period binomial tree to analyze the problem.

Let $n=40$ periods to maturity,

$T=$ term to maturity,

$h=T / n=$ length of one period in years, and

$\hat{r}=e^{-r h}=1+$ interest owed during one period.

Each period let $R$ rise or fall by $u$. Let $\pi=$ the risk-neutral probability of a rise in $R$. Following Sick (1989), we set $\pi$ and $u$ jointly so that the mean and variance of the riskneutral binomial process equal mean and variance of the risk-neutral diffusion. That is, for the binomial process,

$$
\begin{aligned}
E(\Delta R) & =\pi u+(1-\pi)(-u)=u(1-2 \pi) \\
E\left((\Delta R)^{2}\right) & =\pi u^{2}+(1-\pi) u^{2}=u^{2} .
\end{aligned}
$$

For the diffusion process,

$$
\begin{aligned}
E(\Delta R) & =\hat{g} h \\
E\left((\Delta R)^{2}\right) & =\sigma^{2} h+(\hat{g} h)^{2} .
\end{aligned}
$$


Equating (22) and (24)

$$
u=\left(\sigma^{2} h+(\hat{g} h)^{2}\right)^{1 / 2} .
$$

Equating (21) and (23) gives

$$
\pi=1 / 2+\frac{h \hat{g}}{2 u} .
$$

Now create a binomial rent tree with probability $\pi$ and up/down moves $u$ and $-u$. At each point in time (working backward from $T=0$ ), we determine whether it is better to upgrade or continue with the low rent and a live option.

$W(R, T)=\max \left\{R h+\frac{1}{\hat{r}}\left(\pi W_{u}+(1-\pi) W_{-u}\right),\left[k^{*}(R, T)\right]^{\gamma} P(R, T)-c k^{*}(R, T)\right\}$,

where $W_{u}=W(R+u, T-h)$

$W_{-u}=W(R-u, T-h)$

are already calculated because they occur later in the tree.

The first function in equation (27) is the payoff to a strategy of deferring the conversion. The second payoff is the net present value at conversion, that is, the proceeds accruing to converting to an optimal density $k^{*}(R, T)^{\gamma}$ when the price of one unit of land that cannot be converted is $P(R, T)$.

\section{The results}

The best way to study the results is by graphing the relationships among the most interesting variables. The base case in the graphs has an initial annual rent $R=\$ 10$, expected growth $g=\$ 0.50$ per year, annual standard deviation of rent of $\sigma=\$ 2.00$, a riskless interest rate $r=5$ percent per year. The conversion efficiency $\gamma=0.4$ and the cost of one unit of conversion capital is $c=\$ 100$. We will study the characteristics of the conversion problem as these variables are adjusted one at a time and when the lease has various terms $T$ to expiry. Three of the figures show the ratio of the value of leased land to the value of fee-simple land.

Figure 2 uses conversion efficiency $\gamma$ and remaining term to expiry $T$ as explanatory variables. When $\gamma=0$, the land cannot be converted, and we find that 20 -year leased land is worth 45 percent of the value of fee-simple land, while 100-year leased land is worth 98 percent of the value of fee-simple land. As $\gamma$ increases, the conversion option becomes more valuable and leased land is exposed to a heavier discount. If conversion is moderately efficient $(\gamma=0.4), 20$-year leased land falls to 40 percent of the value of fee-simple land and 100-year leased land falls to 94 percent of the value of fee-simple land. 


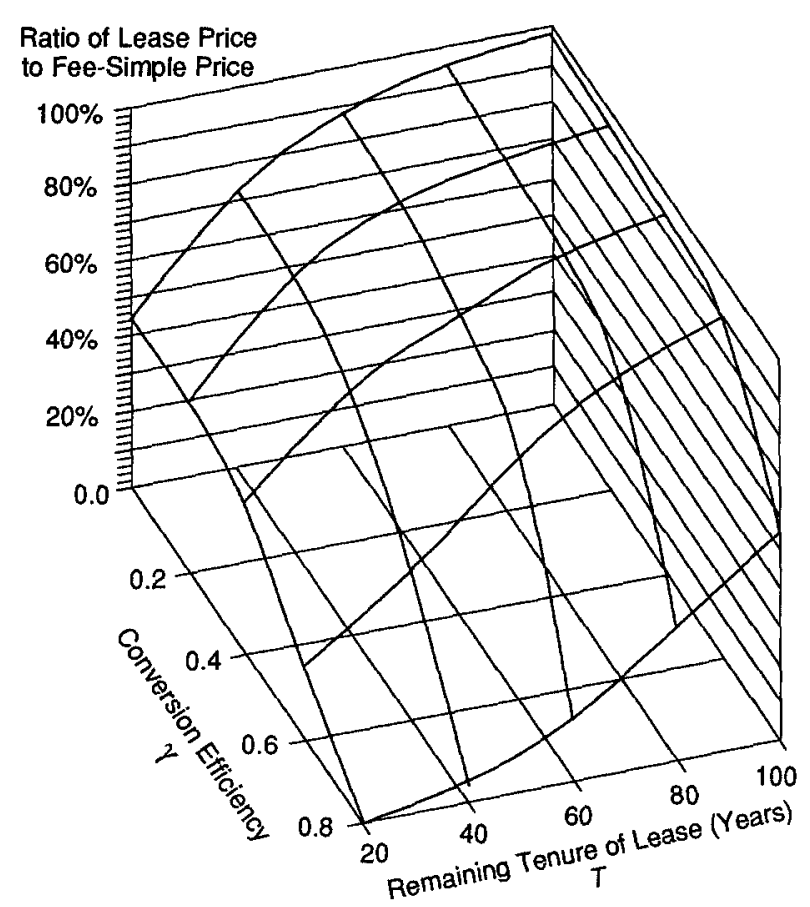

Figure 2. The discount on leased property.

Discounts for 80 -year leased land of 20 percent to 65 percent are obtained when the conversion technology is in the .6 to .8 range. With the assumed production technology, this corresponds to land being 20 percent to 40 percent of property value - a reasonable range. To confirm that this is a plausible level of efficiency, consider Figure 3, which shows that $\gamma=0.7$ implies a plausible conversion density of about 50 to 1 for 80 -year leased land. An efficiency of $\gamma=.6$ gives a conversion density of just 8.5 to 1 for 80 -year leased land.

Real estate investors often use rent multipliers, which are the ratio of property value, $P(R, T)$, to annual (net) rental revenue $R$, that is, the inverse of the rental rate. Figure 4 shows the rent multipliers at the time of conversion for various conversion efficiencies and lease tenures. It shows that an 80-year lease would have a net rent multiplier of approximately 25 or rental rate of 4 percent if $\gamma=0.6$. This is reasonable for single-family residential property.

Figure 5 shows how the leased land is discounted from fee-simple land when the riskless interest rate varies. Large discounts correspond to low interest rates. Low interest rates are only consistent with much higher rent multipliers. Similarly, Figure 6 shows how high rent growth rates can also lead to large discounts on leases. This also leads to higher rent multipliers. Variation in rent volatility, $\sigma$, has approximately equal impacts on both leased and fee-simple values so that the discount increases only slightly as $\sigma$ increases. 


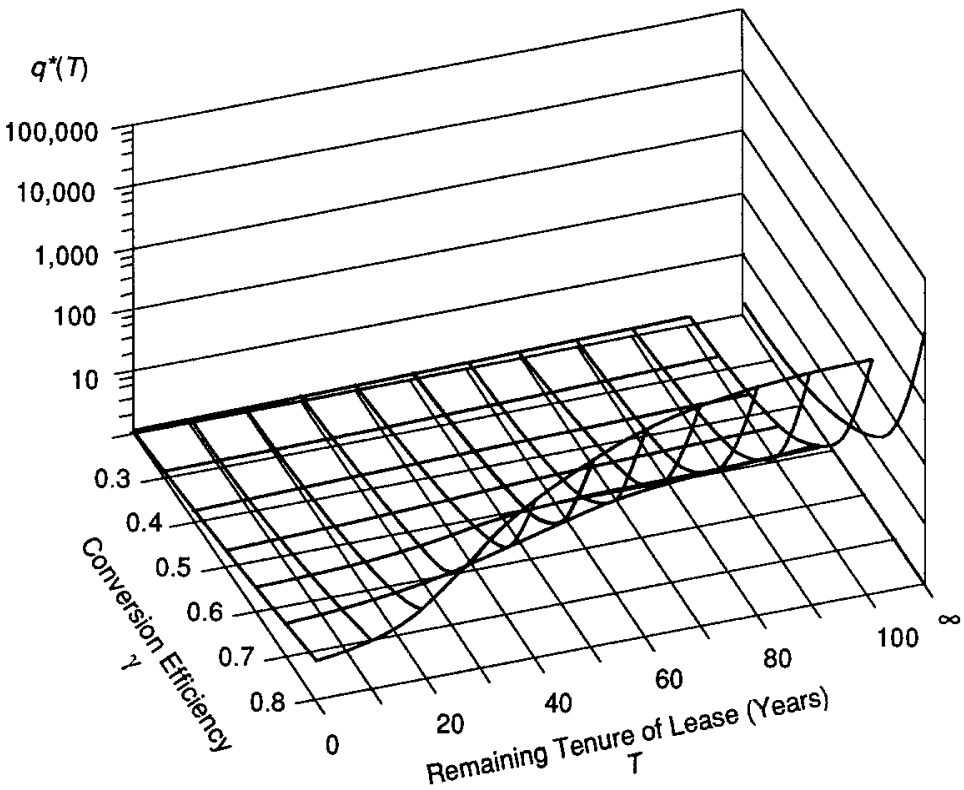

Figure 3. Conversion density, conversion efficiency, and lease tenure.

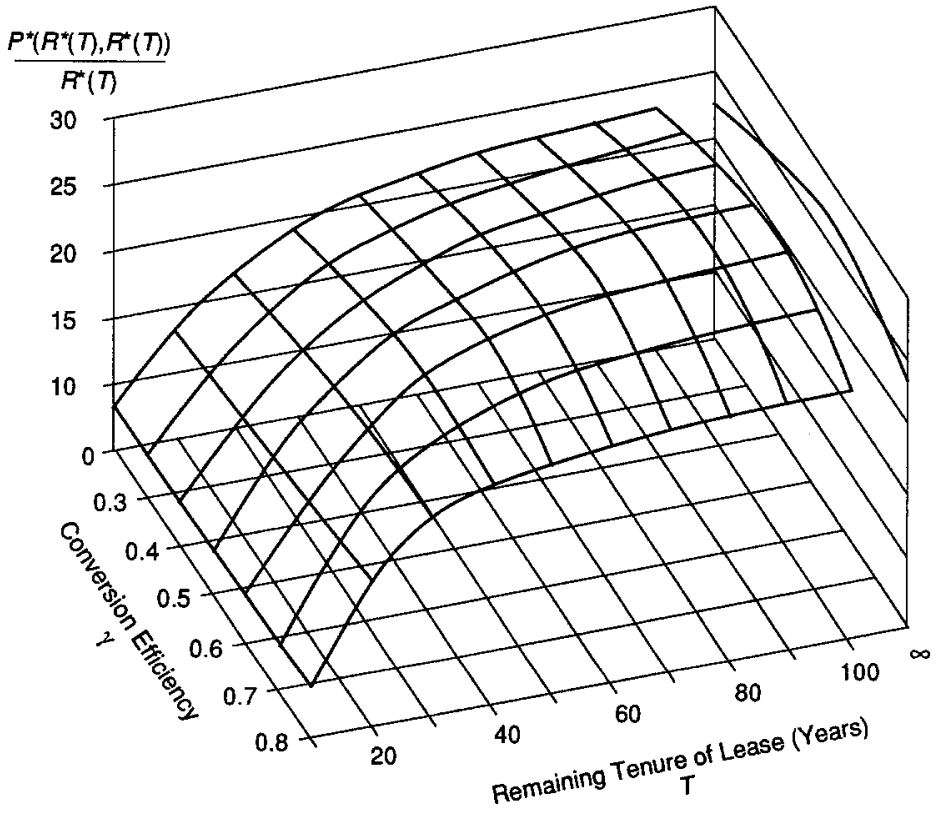

Figure 4. Rent multipliers, conversion efficiency, and lease tenure. 


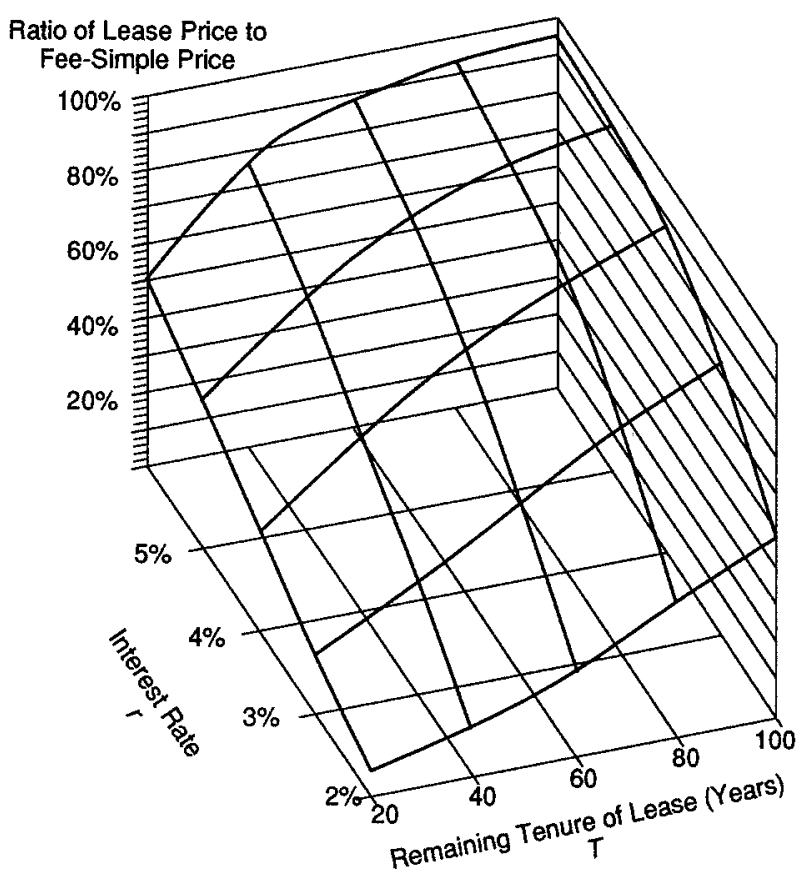

Figure 5. The riskless interest rate and the discount on leased property.

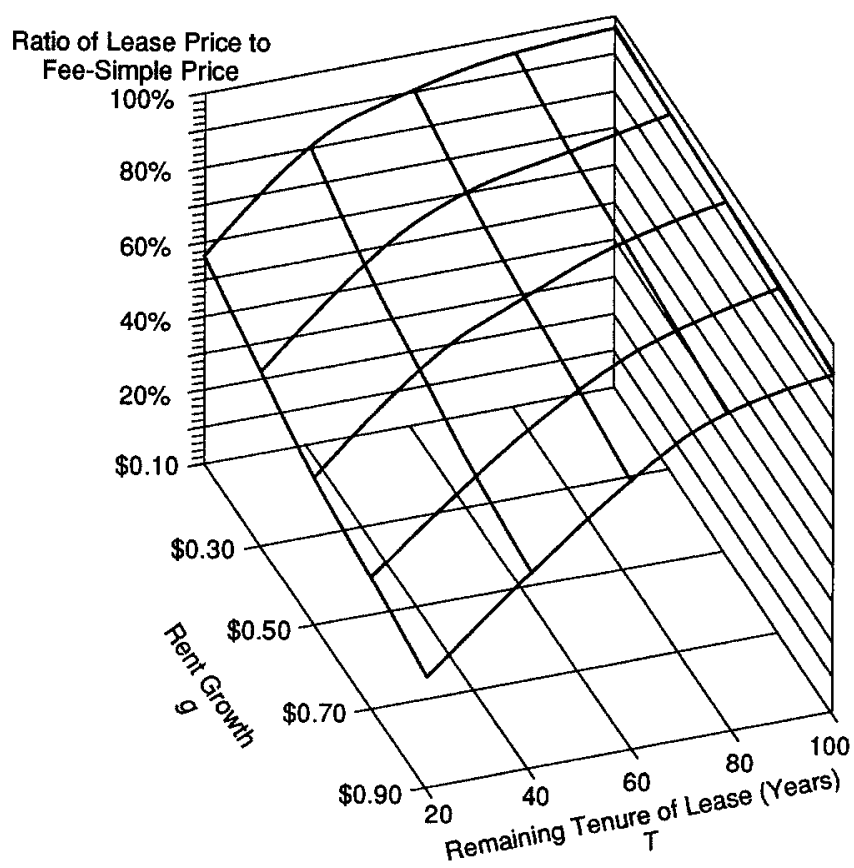

Figure 6. Rent growth and the discount on leased property. 
Finally, Figure 7 shows how the hurdle price $P\left(R^{*}(T), T\right)$, varies with conversion efficiency and tenure. The hurdle price increases with tenure, $T$, because one can afford to wait a bit longer before converting if the clock is not about to expire soon. The behavior of the hurdle price for various conversion efficiencies is quite interesting for long-term leases and fee-simple land. That is, the hurdle price is high if either the conversion process is very efficient or very inefficient. Otherwise the hurdle price is low. If the conversion process is very inefficient (low $\gamma$ ), a high land price is required just to pay off the cost of conversion (using the net present value rule), so land is not converted at low land prices. On the other hand, if the conversion process is very efficient, it pays to set a high hurdle price and develop a mega-project when the hurdle is finally met. By setting the hurdle price high, the net present value of conversion is high, but the conversion is also delayed far into the future, thereby reducing the discounted present value. The delay is worthwhile only if the conversion process is very efficient. Thus the hurdle price increases as conversion efficiency increases for large $\gamma$.

\section{Summary and conclusions}

The option to redevelop explains a large part of the discount between leased and fee-simple land. The discount is larger in the model when conversion efficiency is high, when the interest rate is low, when rent growth is high, or when the uncertainty is high. However, without high rent multipliers, very efficient conversion processes, or short terms to maturity, the full amount of observed discounts in long-term leases cannot be explained by the model alone.

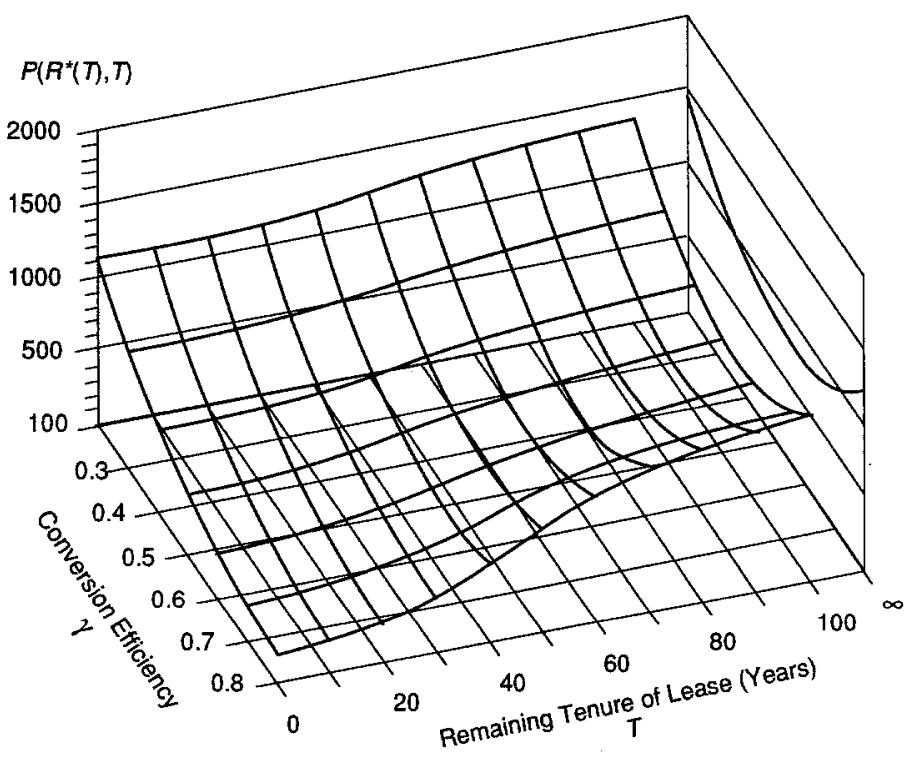

Figure 7. Hurdle price, $P\left(R^{*}(T), T\right)$, conversion efficiency, and tenure. 
There are other reasons why leased property may sell at a discount. First, there are legal risks in a lease contract. For example, Indian bands in Canada have successfully sued the Canadian government to obtain additional compensation or additional rights on existing leases. The Musqueam Band in Vancouver has recently affirmed its right to tax and provide city services to land that was sold as prepaid leases 20 years ago.

Second, our model assumes that only one upgrade will occur during the life of the lease. Allowing for multiple upgrades may affect the discount. Third, we have assumed additive growth and a constant elasticity of capital technology. We know that when growth is multiplicative the value of fee-simple property becomes infinite but the value of leased land does not. Therefore, other processes and production technologies may yield larger discounts.

The model has important implications for efficient land use when leases are in force. When property is encumbered by a long-term lease, redevelopment occurs earlier and at a lower density relative to the optimal values. From a public policy perspective, care must be taken to avoid welfare losses when property is leased.

\section{Acknowledgments}

The financial support of Alberta Energy Corporation and the Office of Real Estate Research of the University of Illinois is gratefully acknowledged. We want to thank Kaushik Amin, Cliff Ball, Jim Follain, Dan Quan, Greg Schwann, Joe Williams, anonymous reviewers, and the participants in workshops at the University of Michigan and M.I.T. for helpful comments.

\section{Notes}

1. Reviews of the real options literature appear in Majd and Pindyck (1987) and Sick (1989).

2. For example, Brennan and Schwartz (1985) and Paddock and associates (1988).

3. See Majd and Pindyck (1987).

4. For clarity, we should note that careful application of NPV rule does not imply that projects should always be undertaken as soon as the conversion NPV rises above zero, because we are working with a stream of mutually exclusive projects. These projects involve various conversion dates and conversion at one date precludes conversion later. In this case the NPV rule advocates taking the project with the highest NPV. Real option theory provides a mechanism for implementing this decision.

5. Capozza and Li (1988) and Clarke and Reid (1988) consider the option to convert fee-simple land to a higher use under uncertainty.

6. We assume additive growth for a number of reasons. First, we have argued elsewhere (Capozza and Sick, 1991) that an additive diffusion more closely represents the cross-sectional variances of small versus large cities. Second, a multiplicative growth process combined with a simple production technology as in equation (1) has no finite solution for fee-simple land. An alternative to our approach would be to combine a decreasing capital elasticity production technology with multiplicative growth. Third, we note that when rent growth is additive, land value follows a mix of additive and multiplicative growth. In the limiting case where current rents are small and option value is proportionately large, value becomes lognormal.

7. See also Capozza and $\mathrm{Li}$ (1988) on a variable density of development.

8. This is consistent with the consumption capital asset pricing model of Breeden (1979) and the single-factor capital asset pricing model of Merton (1973). It is also consistent with the multifactor arbitrage pricing theory 
(APT) of Ross (1976) after a suitable factor rotation. That is, in an APT with $k$ factors $\delta_{1} \ldots \delta_{k}$ and market prices of risk $\gamma_{1} \ldots \gamma_{k}, E(d P / P)=r d t+\Sigma_{j=1}^{k} \gamma_{j} \operatorname{cov}\left(d P / P, d \delta_{j}\right)$. This collapses to a single-factor model by setting $\lambda=1$ and $d f=\Sigma_{j=1}^{k} \gamma_{j} d \delta_{j}$.

9. For example, this equation appears in Merton (1973), Ingersoll (1987), and Sick (1989).

10. See Sick (1989) for a discussion of the solution to this differential equation.

\section{References}

Breeden, D. "An Intertemporal Asset Pricing Model with Stochastic Consumption and Investment Opportunities." Journal of Financial Economics 7 (1979), 265-296.

Brennan, Michael J. and Schwartz, Eduardo S. "Evaluating Natural Resource Investments." Journal of Business 58 (1985), 135-157.

Capozza, Dennis and Li, Y. "A Generalized Model of Land Conversion under Uncertainty." University of Michigan, 1988. Mimeo.

Capozza, Dennis and Sick, Gordon. "Pricing Risky Land." University of Michigan, 1991. Mimeo.

Clarke, H. and Reid, W. "A Stochastic Analysis of Land Development Timing and Property Valuation." Regional Science and Urban Economics 18 (1988), 357-381.

Ingersoll, Jonathan. Theory of Financial Decision Making. Totowa, NJ: Rowman and Littlefield, 1987.

Luzatto, Marc L. "Lease-Purchasing Real Estate." American City and County 102 (1987), 20.

Majd, Saman and Pindyck, Robert S. "Time to Build, Option Value and Investment Decisions." Journal of Financial Economics 18 (1987), 7-27.

McConnell, John J. and Schallheim, James S. "Valuation of Asset Leasing Contracts." Journal of Financial Economics 12 (1983), 237-261.

Myers, S., Dill, D., and Bautista, A. "Valuation of Asset Leasing Contracts." Journal of Finance 31 (1976), 799-819.

Paddock, J.L., Siegel, D.R., and Smith, J.L. "Option Valuation of Claims on Real Assets: The Case of Offshore Petroleum Leases." Quarterly Journal of Economics (August 1988), 479-508.

Ross, S.A. "Risk, Return and Arbitrage." In I. Friend and J. Bicksler, eds., Risk and Return in Finance. Cambridge, MA: Ballinger, 1976.

Sick, G.A. Capital Budgeting with Real Options. New York: Salomon Brothers Center for Financial Research, New York University, Monograph, 1989-3. 